\title{
What predicts the trust of online health information?
}

\author{
Jeong Hyun Kwon ${ }^{1 *}$, Su-Yeon $\mathrm{Kye}^{2^{*}}$, Eun Young Park ${ }^{3}$, Kyung Hee $\mathrm{Oh}^{2}$, Keeho Park ${ }^{1}$ \\ ${ }^{1}$ Cancer Policy Branch, National Cancer Control Institute, National Cancer Center, Goyang; ${ }^{2}$ Cancer Information and Education Branch, \\ National Cancer Control Institute, National Cancer Center, Goyang; ${ }^{3}$ Carcinogenic Hazard Branch, National Cancer Control Institute, National \\ Cancer Center, Goyang, Korea
}

\begin{abstract}
OBJECTIVES: Little attention has been paid to levels of trust in online sources of health information. The objective of this study was to investigate levels of trust in various sources of health information (interpersonal channels, traditional media, and Internet media), and to examine the predictors of trust in health information available on the Internet.

METHODS: A questionnaire was administered to 1,300 people (20 years of age or older), evaluating levels of trust in various sources of health information.

RESULTS: The highest level of trust was expressed regarding interpersonal channels, with hospital physicians regarded as the most trusted source of information age and income showed an association with trust in online information sources. Elderly people were not likely to trust Internet news sources, and high incomes were found to be strongly associated with trust in online sources of information overall.
\end{abstract}

CONCLUSIONS: Public health organizations must consider the predictors for trust in various sources of information in order to employ appropriate media when targeting vulnerable individuals or developing messaging strategies for health professionals.

KEY WORDS: Trust, Internet, Health information

\section{INTRODUCTION}

The general public is exposed to a great amount of health information on websites. And it can be hard to identify credible and accurate health information [1]. The Pew Internet \& American Life Project [2] has reported that $80 \%$ of the people it surveyed were able to search for health information online, suggesting that Internet users are increasingly making use of the availability of online health information. Therefore, it is very

\section{Correspondence: Keeho Park}

Cancer Policy Branch, National Cancer Control Institute, National Cancer Center, 323 Ilsan-ro, Ilsandong-gu, Goyang 410-769, Korea

Tel: +82-31-920-2160, Fax: +82-31-920-2949, E-mail: park.keeho@gmail.com

${ }^{\star}$ Kwon and Kye have contributed equally to this work as joint first author.

Received: Apr 17, 2015, Accepted: Jun 28, 2015, Published: Jun 28, 2015

This article is available from: http://e-epih.org/

(C) 2015, Korean Society of Epidemiology

(C) This is an open-access article distributed under the terms of the Creative Commons Attribution License (http://creativecommons.org/licenses/by/3.0/), which permits unrestricted use, distribution, and reproduction in any medium, provided the original work is properly cited. important that accurate health information is provided.

Most previous studies that have examined the quality or credibility of information have been concerned with multidimensional variables, such as accuracy, trustworthiness, believability, fairness, currency, completeness, bias factors [3-7], and the evaluation of health-related websites [4-8]. Earlier studies have indicated that the most important factor an information source credibility that it can be used to make decisions about the assessment and application of information [9-11]. Other studies have also shown that the credibility of health information sources can vary depending on who offers the information, where they operate, and where the information originates. Previous research about the evaluation of health information has shown that the source of the information has the biggest impact on levels of trust. Therefore, we investigated a representative sample of the population and evaluated their levels of trust in a variety of sources of health information (interpersonal channels, traditional media, and Internet media), as well as predictors of trust in online sources of health information.

Trust has not been definitively conceptualized among social scientists. It is generally agreed that trust involves confidence in 
the reliability of an entity [12], which also entails the evaluated prediction of positive results [13]. In other words, trust in this context involves a user's subjective perceptions when assessing online sources of health information [12]. We also measured levels of trust in various types of online sources of health information. Some previous studies have likewise assessed levels of trust in various sources of health information. One study measured trust in the following eight sources of health information: physicians, family members, telephone advice lines, newspapers, employee assistance programs, advice books, health fairs, and the Internet [14]. Another study estimated trust in the following seven sources of health information: physicians, Internet,TV, family members, magazines, newspapers, and radio [15]. However, neither study assessed how respondents evaluated health information depending on the systemic category of a medium or among various dissimilar sources within a medium. A number of relevant health-related websites dispense information on health [16], as well as websites for non-profit organizations, associations, personal blogs, and portal sites that operate counseling services. It is difficult to find research on levels of trust in the health information that is provided by particular sources. It is therefore necessary to assess this issue by evaluating diverse and widely accessible sources of health information. Our study was concerned with investigating levels of trust in three different sources of health information and examining how demographic factors affected attitudes towards online sources of information.

Previous studies have identified traditional correlates of media credibility, such as sex, age, income, and education $[8,17,18]$. These studies performed demographic comparisons of trust in TV and newspapers. In recent years, a number of studies have studied levels of trust in a wide range of online sources and interactive technologies. Some of these studies were conducted to examine the demographic variables that predicted trust towards online sources $[15,19,20]$. Moreover, one study performed multivariate logistic regression analysis and identified health and functional status (functional limitations due to disability or chronic disease) as factors affecting trust in the Internet as a source of health information [12], and determined that those with poor health status were significantly less likely than their counterparts to trust online sources. In other words, both demographic and health status contribute to levels of trust in the Internet for health information. Furthermore, we suggest that trust in online sources of health information is mediated by individual and family disease history, as an alternative to the previously identified factor of health status. Thus, we explored how demographic variables and disease history affected people's perceptions of trust in online sources of health information. This study is intended to assist in understanding who uses online health information most frequently. We also performed a series of analyses in order to (1) compare the levels of trust in interpersonal channels, traditional media, and online sources of health information, and (2) identify factors associated with trust in online sources of health information. Based on the above considerations, the following research questions $(\mathrm{RQ})$ were developed:

RQ1: How do levels of trust differ among interpersonal channels, traditional media, and Internet sources of health information?

RQ2: How do demographics affect levels of trust in Internet sources of health information?

RQ3: How does disease history affect levels of trust in Internet sources of health information?

\section{MATERIALS AND METHODS}

\section{Participants}

The participants in this cross-sectional study were chosen by age- stratified and region-stratified random sampling based on the Korean census of 2007. The respondents consisted of 1,300 adults across the nation between 20 and 70 years of age, which was an appropriate sample size to represent the population (the alpha level was 0.05 , the acceptable error was $2.7 \%$, and the standard deviation of the scale was 0.05) [21]. The data were collected during September 2010 for five weeks via a questionnaire survey that took each respondent average 15 minutes to complete. The response rate was $63 \%$, which was acceptable in light of previously reported response rates [22]. The institutional review board of the National Cancer Center of Korea approved this study.

\section{Measurement of variables}

The purpose of this survey was to evaluate trust in three different sources of health information (interpersonal, traditional, and the Internet), and to investigate factors associated with trust in online sources of health information. Trust refers to a user's subjective assessment of sources of health information.

\section{Demographics and disease history}

The demographic variables used in this study were sex, age, education, annual household income, individual disease history, and family disease history. The variables regarding disease history were dichotomized as yes and no.

\section{Trust in interpersonal sources of health information}

This was assessed using the following measure: "How much do you trust the following sources of health information?" Six interpersonal sources were provided: physician (clinic), physician (hospital), pharmacist, doctor of Oriental medicine, family 
members, and friends. Respondents were asked to answer the question using a five-point Likert scale, with responses ranging from 1 (strongly disagree) to 5 (strongly agree).

\section{Trust in traditional media sources of health information}

This category included national TV, cable TV, magazines, newspapers, free newspapers, and radio.

\section{Trust in Internet sources of health information}

This category included government organizations, private healthcare providers, non-profit health organizations, question and answer services on the web, patient organizations, Internet news, blogs by physicians, and blogs by laypeople.

\section{Data analysis}

The chi-squared test was used to analyze the relationship of demographic and health status with trust in Internet sources. Binary multivariate logistic regression was performed, using trust in Internet media sources as the dependent variable and demographic and health status as independent variables. Two groups (low vs. high) were recoded as dichotomous variables ( 0 = strongly disagree/disagree/neutral, 1 = agree/strongly agree), corresponding to the level of trust in each Internet source. Variables that were significant $(\mathrm{p}<0.1)$ upon bivariate analysis were used to determine the binary multivariate relationships of demographic and health status with trust in Internet media sources. We included all covariates that were significant upon bivariate analysis in the binary multivariate logistic regression. The data were analyzed using the SPSS version 16.0 (SPSS Inc., Chicago, IL, USA).

\section{RESULTS}

\section{Demographic characteristics}

Table 1 presents the demographic characteristics of the study population. More than half of the respondents were high school graduates or currently in college $(52.4 \%)$ with a moderate income $(57.6 \%)$. Respondents with no individual disease history disease accounted for $86.8 \%$ of the sample, while $26.5 \%$ of respondents reported a family disease history.

\section{Trust in interpersonal, traditional, and online sources of health information}

This study compared the proportion of responses indicating trust in three different categories of health information sources. Hospital physicians $(85.9 \%)$ were the most trusted source of health information. Blogs by ordinary people $(20.2 \%)$ were the least trusted source.

Among the three different categories of information sources,
Table 1. Demographic characteristics

\begin{tabular}{lr}
\hline Variables & $n(\%)$ \\
\hline Sex & \\
$\quad$ Male & $662(50.9)$ \\
Female & $638(49.1)$ \\
Age (yr) & \\
$20-30$ & $245(18.8)$ \\
$31-40$ & $323(24.8)$ \\
$41-50$ & $347(26.7)$ \\
$51-60$ & $250(19.2)$ \\
$61-70$ & $135(10.5)$ \\
Education & \\
Middle school graduate & $136(10.5)$ \\
High school graduate & $681(52.4)$ \\
College graduate or higher & $483(37.1)$ \\
Annual household income (US dollar) & \\
$\quad<25,000$ & $363(27.9)$ \\
$25,000-49,999$ & $749(57.6)$ \\
$\geq 50,000$ & $188(14.5)$ \\
Individual disease history & \\
No & $1,129(86.8)$ \\
Yes & $171(13.2)$ \\
Family disease history & \\
No & $956(73.5)$ \\
Yes & $344(26.5)$ \\
\hline
\end{tabular}

interpersonal channels $(59.7 \%)$ scored the highest. Traditional media sources $(47.8 \%)$ came next, followed by online sources (40.4\%) (Figure 1). Within each category, hospital physicians were most trusted within the interpersonal sources of information, national TV within the traditional media, and government organizations within the online sources.

\section{Factors associated with trust in online sources of health information}

In order to identify predictive factors associated with trust in online sources of health information, independent variables (demographic/health status) were identified, the chi-squared test was performed, and binary multivariate logistic regression analyses were implemented on variables found to be significant $(\mathrm{p}<$ 0.1 ) in bivariate analysis (Table 2). The results of the chi-squared test were as follows: education $(p=0.037)$, income $(p=0.002)$, and individual disease history $(\mathrm{p}=0.037)$ were significantly associated with trust in online sources associated with government organizations; income $(\mathrm{p}<0.001)$ and individual disease history $(\mathrm{p}=0.038)$ with trust in online sources associated with private healthcare providers; income $(p=0.013)$, education $(p=0.077)$, and individual disease history $(p=0.086)$ with trust in online sources associated with non-profit health organizations; age $(\mathrm{p}=$ 0.039 ), income ( $<<0.001)$, education $(\mathrm{p}=0.098)$, and individual disease history $(\mathrm{p}=0.065)$ with trust in online question and answer services; income $(\mathrm{p}<0.001)$, individual disease history $(\mathrm{p}=0.064)$, and family disease history $(\mathrm{p}=0.072)$ with trust in 


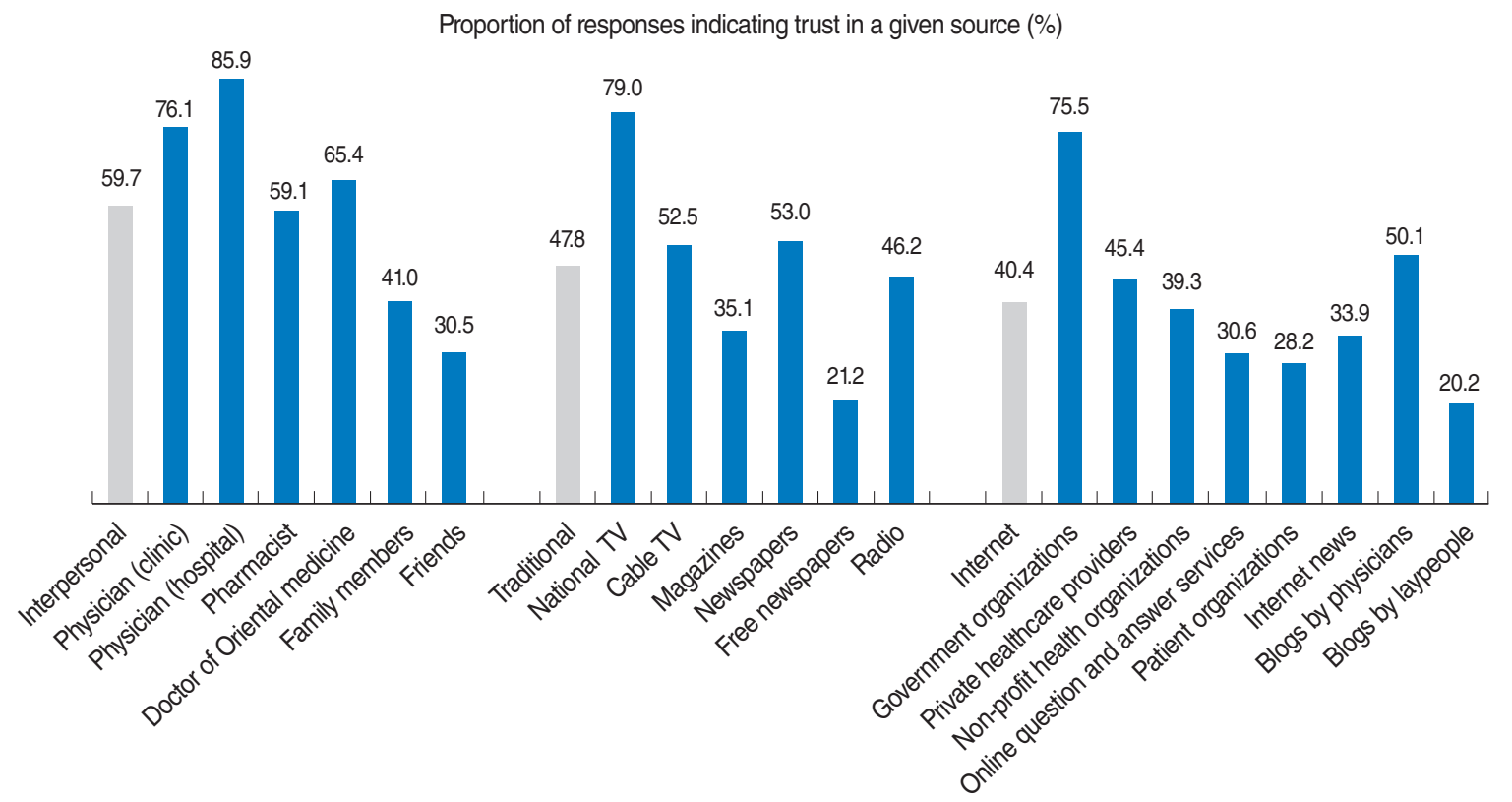

Figure 1. Comparison of levels of trust in interpersonal channels, traditional media, and online sources of health information.

Table 2. Factors associated with trust in various online sources of health information

\begin{tabular}{|c|c|c|c|c|c|c|c|c|}
\hline \multirow[b]{2}{*}{ Characteristics } & \multicolumn{8}{|c|}{ Internet media } \\
\hline & $\begin{array}{l}\text { Government } \\
\text { organizations }\end{array}$ & $\begin{array}{l}\text { Private health- } \\
\text { care providers }\end{array}$ & $\begin{array}{c}\text { Non-profit } \\
\text { health organi- } \\
\text { zations }\end{array}$ & $\begin{array}{l}\text { Online ques- } \\
\text { tion and an- } \\
\text { swer services }\end{array}$ & $\begin{array}{c}\text { Patient } \\
\text { organizations }\end{array}$ & $\begin{array}{l}\text { Internet } \\
\text { news }\end{array}$ & $\begin{array}{l}\text { Blogs by } \\
\text { physicians }\end{array}$ & $\begin{array}{l}\text { Blogs by } \\
\text { laypeople }\end{array}$ \\
\hline $\begin{array}{l}\text { Sex } \\
\text { Male } \\
\text { Female }\end{array}$ & & & & & & & & \\
\hline $\begin{array}{c}\text { Age (yr) } \\
20-30 \\
31-40 \\
41-50 \\
51-60 \\
61-70\end{array}$ & & & & $\begin{array}{c}\text { Reference } \\
0.7(0.5,1.1) \\
0.8(0.5,1.1) \\
0.6(0.4,0.9)^{\star} \\
0.6(0.3,0.9)^{\star}\end{array}$ & & $\begin{array}{c}\text { Reference } \\
0.7(0.5,1.1) \\
0.8(0.5,1.1) \\
0.6(0.4,0.9)^{\star} \\
0.4(0.2,0.7)^{\star \star}\end{array}$ & & \\
\hline $\begin{array}{l}\text { Education } \\
\text { Middle school graduate } \\
\text { High school graduate } \\
\text { College graduate }\end{array}$ & $\begin{array}{c}\text { Reference } \\
1.1(0.7,1.8) \\
1.3(0.8,2.1)\end{array}$ & $\begin{array}{c}\text { Reference } \\
1.1(0.7,1.7) \\
1.2(0.8,1.8)\end{array}$ & $\begin{array}{c}\text { Reference } \\
1.3(0.8,1.9) \\
1.3(0.9,2.1)\end{array}$ & $\begin{array}{c}\text { Reference } \\
0.8(0.5,1.3) \\
0.9(0.6,1.6)\end{array}$ & & $\begin{array}{c}\text { Reference } \\
1.1(0.7,1.7) \\
1.1(0.6,1.8)\end{array}$ & & \\
\hline $\begin{array}{l}\text { Annual household income } \\
\quad<25,000 \\
25,000-49,999 \\
\geq 50,000\end{array}$ & $\begin{array}{l}\text { (US dollar) } \\
\text { Reference } \\
1.5(1.1,2.0)^{\star \star} \\
1.8(1.2,2.8)^{\star \star}\end{array}$ & $\begin{array}{l}\text { Reference } \\
1.5(1.1,2.0)^{\star \star} \\
2.1(1.4,3.0)^{\star}\end{array}$ & $\begin{array}{c}\text { Reference } \\
1.1(0.8,1.5) \\
1.5(1.1,2.2)^{\star}\end{array}$ & $\begin{array}{l}\text { Reference } \\
1.7(1.2,2.3)^{\star \star} \\
1.9(1.3,2.9)^{\star \star}\end{array}$ & $\begin{array}{l}\text { Reference } \\
1.6(1.1,2.1)^{\star \star} \\
1.8(1.2,2.7)^{\star \star}\end{array}$ & $\begin{array}{l}\text { Reference } \\
1.3(1.1,1.7)^{\star} \\
2.2(1.5,3.3)^{\star \star \star}\end{array}$ & $\begin{array}{l}\text { Reference } \\
1.4(1.1,1.8)^{\star \star} \\
2.1(1.5,3.1)^{\star \star \star}\end{array}$ & $\begin{array}{c}\text { Reference } \\
1.4(1.1,1.9)^{\star} \\
* 1.5(1.1,2.4)^{\star}\end{array}$ \\
\hline $\begin{array}{l}\text { Individual disease history } \\
\text { No } \\
\text { Yes }\end{array}$ & $\begin{array}{c}\text { Reference } \\
0.8(0.5,1.2)\end{array}$ & $\begin{array}{c}\text { Reference } \\
0.8(0.5,1.1)\end{array}$ & $\begin{array}{c}\text { Reference } \\
0.8(0.5,1.1)\end{array}$ & $\begin{array}{c}\text { Reference } \\
0.8(0.5,1.2)\end{array}$ & $\begin{array}{c}\text { Reference } \\
0.8(0.5,1.2)\end{array}$ & & $\begin{array}{c}\text { Reference } \\
0.7(0.5,1.1)\end{array}$ & \\
\hline $\begin{array}{l}\text { Family disease history } \\
\text { No } \\
\text { Yes }\end{array}$ & & & & & $\begin{array}{c}\text { Reference } \\
0.8(0.6,1.1)\end{array}$ & & & \\
\hline
\end{tabular}

Values are presented as odds ratio ( $95 \%$ confidence interval).

${ }^{\star} p<0.05,{ }^{* *} p<0.01,{ }^{* *} p<0.001$.

online sources associated with patient organizations; age $(\mathrm{p}<$ $0.001)$, income $(\mathrm{p}<0.001)$, education $(\mathrm{p}=0.033)$, and individu- al disease history $(p=0.078)$ with trust in Internet news; income $(\mathrm{p}<0.001)$ and individual disease history $(\mathrm{p}=0.016)$ with trust 
in blogs by physicians; and income $(\mathrm{p}=0.070)$ with trust in blogs by laypeople.

Higher income levels were generally associated with greater trust in online sources of health information. Respondents aged 51 to 70 years were not likely to trust Internet news sources. Respondents with a moderate income (odds ratio $[\mathrm{OR}]=1.5$ ) or a high income $(\mathrm{OR}=1.8)$ were likely to trust Internet sources associated with government organizations than those with a low income. Respondents with a high income were twice as likely $(\mathrm{OR}=2.1)$ to trust online sources associated with private healthcare providers than those with a low income. High incomes were associated with trusting Internet sources affiliated with non-profit health organizations $(\mathrm{OR}=1.5)$. Respondents with a moderate income $(\mathrm{OR}=1.7)$ or a high income $(\mathrm{OR}=1.9)$ were almost twice as likely to trust online question and answer services than respondents with a low income individuals, whereas older respondents were much less likely to trust such services ( 51 to 60 years, $\mathrm{OR}=0.6 ; 61$ to 70 years, $\mathrm{OR}=0.4$ ). Higher levels of income were associated with more trust in sources affiliated with patient organizations (moderate income, $\mathrm{OR}=1.6$; high income, $\mathrm{OR}=1.8$ ). Likewise, respondents with a moderate income $(\mathrm{OR}=1.3)$ or a high income $(\mathrm{OR}=2.2)$ were likely to trust Internet news sources, whereas older respondents (51 to 60 years, $\mathrm{OR}=0.6 ; 61$ to 70 years, $\mathrm{OR}=0.4$ ) were much less likely to trust such sources. Higher income levels were associated with greater trust in blogs by physicians (moderate income, $\mathrm{OR}=1.4$; high income, $\mathrm{OR}=2.1)$. Similarly, respondents with a moderate income $(\mathrm{OR}=1.4)$ or a high income $(\mathrm{OR}=1.5)$ were more likely to trust blogs by laypeople.

Overall, a high level of income was associated with trust in most online sources of health information. Meanwhile, disease history (individual or family) was not significantly related to levels of trust in Internet sources associated with government organizations, private healthcare providers, non-profit health organizations, question and answer services on the web, patient organizations, Internet news, blogs by physicians, and blogs by laypeople.

\section{DISCUSSION}

\section{Principal results}

This study compared levels of trust in three different sources of health information, and identified factors associated with trust in various online sources of health information. The results of comparing levels of trust among three different sources revealed that Koreans showed the higher level of trust in interpersonal sources, whereas the least trusted source was online media. These results demonstrate that a majority of people still primarily rely on interpersonal channels for health information. Hospital phy- sicians, national TV, and Internet sources associated with government organizations were the most trusted sources among the three categories, and were generally regarded as professional and objective channels of information. These findings were quite similar to those of prior studies concerning the impact of information providers and source attribution on trust $[16,17$, 23]. Abel \& Wirth [17] showed that nearly all groups in their study perceived national TV to be more credible than newspapers, if confronted with conflicting local news reports. Marwick [16] reported that health information provided by a physician was the most important source of information regardless of socioeconomic status. Additionally, Hesse et al. [15] found that physicians remained the most highly trusted information source among patients, with $62.4 \%$ of adults expressing a great degree of trust in their physicians. Our results suggest that online sources of health information are not considered as trustworthy and professional, although many such sources exist. We may assume that the reason is to be depending interpersonal channel such as health professionals or old media due to a lack of credible and official health information sources on the Internet.

One of the goals of this study was to investigate factors associated with trust in online sources of health information. The findings regarding RQ2 and RQ3 can be summarized as follows: income had a significant impact on trust in all online sources, including government organizations, private healthcare providers, non-profit health organizations, online question and answer services, patient organizations, Internet news, blogs by physicians, and blogs by laypeople. It can be inferred that respondents with a high income could easily access the Internet, and would therefore be frequently exposed to online health information.

The older people were, the less they tended to regard Internet sources as credible. We believe that individuals who are elderly and have a low income were less likely to perceive the Internet as a credible information source because they tend to have lower levels of Internet use, and thus were less likely to be familiar with the Internet. These results are consistent with recent studies on trust in online sources of health information [15, 23]. In particular, Hesse et al. [15] showed that those who searched online the most tended to have higher incomes.

This study showed that education level was not related to trust in online health information. This is in agreement with Ye's [24] study, but it does contradict other studies $[12,15,23]$. It is possible that education level does not necessarily increase consumer self-confidence in dealing with a variety of online sources of health information. Shon et al. [25] reported that even highly educated people had trouble identifying misleading health information. Consequently, both individuals with a higher level of education and those with a lower level of education may have difficulty judging the credibility of online health information, and therefore showed similar results in the present study. Ye's 
[24] study showed that $30.4 \%$ of those with at least some college education reported that it was "hard" or "very hard" to understand medical statistics and that $49.5 \%$ of the respondents with a high school education or less reported the same. Therefore, organizations responsible for health websites need to ensure that information can be readily located and presented in ways that can be easily understood by the general public.

Some limitations should be noted regarding the interpretation of these results. This was a cross-sectional study, and we cannot draw any conclusions about causality or mediation based on our analyses. Furthermore, unmeasured characteristics may have influenced levels of trust in online health information, such as information needs. However, we did find that the predictability of factors related to trust in online sources of health information depended on the nature of the source, thus suggesting that it may be necessary to apply health information strategies differently for each source. Our results may inform the development of practical guidelines. Public health organizations should offer health education programs or comprehensive community services that customize health information for low-income individuals or those who lack the ability to use online health information. The provision of aid programs or services should focus on universal resources that can be used by everyone, because the recipients of such services may then become more aware of accessible resources and gradually perceive the usefulness of information provided by the organizations in question.

In the future, it is necessary to examine the factors affecting trust in a range of interpersonal channels and traditional media sources, as well as to perform additional analyses to identify other factors influencing trust in sources of health information beyond demographics and disease history.

\section{ACKNOWLEDGEMENTS}

This study was supported by National Cancer Center (grant no. 1310260-3).

\section{CONFLICT OF INTEREST}

The authors have no conflicts of interest to declare for this study.

\section{ORCID}

Jeong Hyun Kwon http://orcid.org/0000-0002-8888-8125

Su-Yeon Kye http://orcid.org/0000-0003-2535-3518

EunYoung Park http://orcid.org/0000-0003-4859-6782

Kyung Hee Oh http://orcid.org/0000-0002-0186-4172
Keeho Park http://orcid.org/0000-0002-0186-4172

\section{REFERENCES}

1. Morahan-Martin JM. How internet users find, evaluate, and use online health information: a cross-cultural review. Cyberpsychol Behav 2004;7:497-510.

2. Fox S. Online health search 2006; 2006 [cited 2010 Aug 10]. Available from: http://www.pewinternet.org/2006/10/29/online-health-search-2006/.

3. Abdulla RA, Garrison B, Salwen M, Driscoll P, Casey D. The credibility of newspapers, television news, and online news. In: Education in Journalism and Mass Communication, Annual Convention; 2002 Aug 9; Miami Beach, FL, USA. Coral Gables: School of Communication University of Miami; 2013, p. 1-30.

4. Flanagin AJ, Metzger MJ. Perceptions of internet information credibility. Journalism Mass Commun Q 2000;77:515-540.

5. Kiousis S. Public trust or mistrust? Perceptions of media credibility in the information age. Mass Commun Soc 2001;4:381-403.

6. Morahan-Martin J, Anderson CD. Information and misinformation online: recommendations for facilitating accurate mental health information retrieval and evaluation. Cyberpsychol Behav 2000;3:731746.

7. Rimmer T, Weaver D. Different questions, different answers? Media use and media credibility. Journalism Mass Commun Q 1987;64:2844.

8. Becker LB, Cobbey RE, Sobowale IA. Public support for the press. Journalism Mass Commun Q 1978;55:421-430.

9. Bates BR, Romina S, Ahmed R, Hopson D. The effect of source credibility on consumers' perceptions of the quality of health information on the Internet. Med Inform Internet Med 2006;31:45-52.

10. Hoffman-Goetz L, Clarke JN. Quality of breast cancer sites on the World Wide Web. Can J Public Health 2000;91:281-284.

11. Walther JB, Wang Z, Loh T. The effect of top-level domains and advertisements on health web-site credibility. J Med Internet Res 2004; 6:e24.

12. Zulman DM, Kirch M, Zheng K, An LC. Trust in the internet as a health resource among older adults: analysis of data from a nationally representative survey. J Med Internet Res 2011;13:e19.

13. Govier T. Social trust and human communities. Montreal: McGillQueen's University Press; 1997, p. 3.

14. Pennbridge J, Moya R, Rodrigues L. Questionnaire survey of California consumers' use and rating of sources of health care information including the Internet. West J Med 1999;171:302-305.

15. Hesse BW, Nelson DE, Kreps GL, Croyle RT, Arora NK, Rimer BK, et al. Trust and sources of health information: the impact of the Internet and its implications for health care providers: findings from the first Health Information National Trends Survey. Arch Intern Med 2005; 165:2618-2624.

16. Marwick C. Ensuring ethical internet information. JAMA 2000;283: $1677-1678$

17. Abel JD, Wirth MO. Newspaper vs. TV credibility for local news. Journalism Mass Commun Q 1977;54:371-375.

18. Gunther AC. Biased press or biased public? Attitudes toward media coverage of social groups. Public Opin Q 1992;56:147-167.

19. Donohue JM, Huskamp HA, Wilson IB, Weissman J. Whom do older adults trust most to provide information about prescription drugs? Am J Geriatr Pharmacother 2009;7:105-116.

20. Dutta-Bergman MJ. Primary sources of health information: compari- 
sons in the domain of health attitudes, health cognitions, and health behaviors. Health Commun 2004;16:273-288.

21. Bartlett JE, Kotrlik JW, Higgins CC. Organizationl research: determining appropriate sample size in survey research. Inf Technol Learn Perform J 2001;19:43-50.

22. Singleton R, Straits BC. Approaches to social research. 4th ed. New York: Oxford University Press; 2005, p. 145.

23. Marrie RA, Salter AR, Tyry T, Fox RJ, Cutter GR. Preferred sources of health information in persons with multiple sclerosis: degree of trust and information sought. J Med Internet Res 2013;15:e67.

24. Ye Y. Correlates of consumer trust in online health information: findings from the health information national trends survey. J Health Commun 2011;16:34-49.

25. Shon J, Marshall J, Musen MA. The impact of displayed awards on the credibility and retention of Web site information. Proc AMIA Symp 2000:794-798. 